\title{
A Retrospective Analysis of the Initial Effect of COVID-19 on German Prehospital Care During Lockdown in Germany
}

This article was published in the following Dove Press journal: Open Access Emergency Medicine

\section{Marcus Örgel (D) \\ Manfred Gogol' \\ Tilman Graulich' \\ Mohamed Omar' \\ Alexander Ranker (iD ${ }^{2}$ \\ Christian Böttcher ${ }^{\prime}$ \\ Emmanouil Liodakis' \\ Christian Krettek (iD) \\ Christian Macke'}

'Trauma Department, Hannover Medical School, Hanover, Germany; ${ }^{2}$ Department of Rehabilitation Medicine, Hannover Medical School, Hanover, Germany
Correspondence: Marcus Örgel Department for Traumatology, Hannover Medical School (MHH), Carl - Neuberg Straße I, Hannover, 30625, Germany Tel +495II 5322099

Email Oergel.Marcus@mh-hannover.de
Introduction: This retrospective cohort analysis examines the impact of the COVID-19 pandemic in the prehospital setting in Germany. The data of two emergency physician response units of a northern German region with 1.2 million citizens was analyzed retrospectively.

Materials and Methods: We analyzed the period March 16 to April 16 for the year 2020 when the lockdown took place in Germany and compare the results for the same period for the year 2019 and 2018. 1004 patients were included. Demographic data, the type of rescue missions, the number of missions per day, the National Advisory Committee for Aeronautics Score (NACA-score), the frequency of respiratory emergencies (COVID-19 and non-COVID -19 associated), as well as the number of deaths were documented.

Results: Mean age was $62.3 \pm 24.8$ years and 576 (56.5\%) were male. Number of missions were 397, 403 and 333 in 2018, 2019 and 2020 respectively. The control room registered a $22 \%$ reduction of rescue missions for the year 2020. Even the amount of emergency calls via the emergency number 112 was reduced by $17.4 \%$ between 2018 and 2020.150 (14.9\%) missions were due to respiratory emergencies. In 202010 missions (28.6\% of respiratory emergencies) were COVID-19 related. In 2020 the NACA score increased significantly.

Conclusion: We found a decreasing effect of the COVID-19 pandemic in Germany on the number of emergency calls as well as missions, and an increase of the severity of cases in preclinical care for a northern German region with 1.2 million citizens. The effect of these findings caused by COVID-19 on the health care system remains to be seen.

Keywords: emergency medicine, SARS-CoV-2, COVID-19, prehospital care, emergency physician response units, pandemic

\section{Background}

Since the COVID-19 pandemic $^{1-4}$ started in China in December 2019, Europe has become a center of this new disease by number of cases and deaths. Germany is less affected with a case fatality proportion ${ }^{5,6}$ (CFP) of 0.041 compared to Italy $(0.137),{ }^{7}$ Spain $(0.102)^{7}$ or France $(0.148) .{ }^{7}$ Germany is, with its absolute number of cases $(n=165,745)$ ranked 6 in Europe after Russia, Spain, UK, Italy, and France. Some authors report during the pandemic of less patient treatments due to heart disease or stroke, ${ }^{8,9}$ and that vaccination rates were lower than in former years (Morbidity and Mortality Weekly Report 2020 [MMWR]). ${ }^{10}$ The authors also noticed fewer medical emergencies in the emergency room of our hospital as well as a lower number of emergency calls for the hospital-based physician 
response unit (PRU) and air ambulance (HEMS [helicopter emergency medical service]).

\section{Objectives}

This study compares during lockdown in Germany while the COVID-19 pandemic six parameters (1-6) in 2020 with the two previous years of 2018 and 2019 to identify the influence of the COVID-19 pandemic of the prehospital emergency system: (1) to quantify for each year number of emergency calls and (2) subsequent rescue missions, (3) number of respiratory diseases and (4) COVID-19-associated diseases, as well as (5) the severity of the diseases and (6) number of deaths. We suggest that the COVID-19 pandemic has an impact on all of these aspects in the prehospital emergency system.

\section{Methods}

\section{Study Design and Setting}

This retrospective single center cohort analysis included all rescue missions of a physician response unit (PRU, 24/ 7 on service) and air ambulance (HEMS, 07:00 a.m./sunrise to sunset on service) that were conducted from March 16 to April 16, 2020, the time when the lockdown took place in Germany and during the same period in 2018 and 2019. The PRU and HEMS are located at the Trauma Department at Hannover Medical School (MHH), a level 1 trauma center, which is a university hospital in Lower Saxony, Germany, with approximately 1600 inpatient beds. Other PRUs and HEMS in lower Saxony were not included.

Furthermore, a survey of all emergency calls and rescue missions carried out in the city and region of
Hanover, an area with 1.2 million citizens, was conducted by Hanover Fire Department. The control room, run by Hanover Fire Department, coordinates overall one primary HEMS (air ambulance [helicopter emergency medical service]), five PRUs (physician response unit) for the city and seven PRUs for the greater area of Hannover. In addition, the control room coordinates a second HEMS too, whose primary task is the physician assisted airborne secondary transport of critically ill patients between hospitals.

A potential confounder of this study could be the varying number of emergency physicians assigned during this time period with different levels of medical education and individual experience in emergency medicine.

\section{Participants and Data Assessment}

For the above-mentioned period, age, gender and emergency characteristics (traumatology, internal medicine, neurology, psychiatry, pediatrics or gynecology, Table 1) of all patients as well as the number of emergency calls per day were obtained. We looked at disease severity with the National Advisory Committee for Aeronautics (NACA) score $(0-7,0=$ no injury or illness, $7=$ death, detailed information is shown in supplementary material), respiratory emergencies and the likelihood of association with COVID-19, and deaths. The NACA score was prospectively documented in the medical reports. Data assessment was performed anonymously by two of the authors.

Additionally, we documented the number of emergency calls received by Hanover Fire Department. Considering the total number of infections and deaths

Table I Percentage Distribution of the Emergency Physician Missions

\begin{tabular}{|c|c|c|c|c|c|c|c|c|c|}
\hline \multirow{2}{*}{$\begin{array}{l}\text { Type of Rescue } \\
\text { Mission }\end{array}$} & \multicolumn{4}{|c|}{ PRU* } & \multicolumn{4}{|c|}{ HEMS** } & \multirow{2}{*}{$\begin{array}{c}\text { PRU + HEMS } \\
\text { n (\%) }\end{array}$} \\
\hline & $\begin{array}{l}2018 \\
\text { n (\%) }\end{array}$ & $\begin{array}{l}2019 \\
\text { n (\%) }\end{array}$ & $\begin{array}{l}2020 \\
\text { n (\%) }\end{array}$ & $\begin{array}{l}\text { Total } \\
\text { n (\%) }\end{array}$ & $\begin{array}{l}2018 \\
\text { n (\%) }\end{array}$ & $\begin{array}{l}2019 \\
\text { n (\%) }\end{array}$ & $\begin{array}{l}2020 \\
\text { n (\%) }\end{array}$ & $\begin{array}{l}\text { Total } \\
\text { n (\%) }\end{array}$ & \\
\hline Traumatology & $19(8.2)$ & 28 (II.9) & $26(12.9)$ & $73(10.9)$ & $53(4 I . I)$ & 45 (39.1) & $46(48.7)$ & $144(42.6)$ & $217(22.6)$ \\
\hline Internal Medicine & $169(72.8)$ & $162(68.6)$ & I 48 (73.6) & 479 (7I.6) & $62(51.8)$ & $56(47.1)$ & $41(46.0)$ & $159(48.5)$ & $638(63.1)$ \\
\hline Neurology & $30(12.9)$ & $36(15.3)$ & $22(10.9)$ & $88(13.2)$ & $8(6.4)$ & $15(12.3)$ & $3(2.7)$ & $26(7.4)$ & II4 (II.0) \\
\hline Psychiatric & $6(2.6)$ & $5(2.1)$ & $2(1.0)$ & $13(1.3)$ & $0(0.0)$ & $0(0.0)$ & $\mathrm{I}(\mathrm{I} .8)$ & I (I.0) & $14(1.2)$ \\
\hline Pediatric & $4(1.7)$ & $3(1.3)$ & $2(1.0)$ & $9(1.9)$ & I (0.7) & I (0.7) & $2(0.9)$ & $4(0.3)$ & $13(1.3)$ \\
\hline Gynecology & $4(1.7)$ & $2(0.8)$ & I (0.5) & $7(1.0)$ & $0(0.0)$ & I (0.7) & $0(0.0)$ & I (0.3) & $8(0.8)$ \\
\hline
\end{tabular}

Abbreviations: *PRU, physician response unit; **HEMS, air ambulance (helicopter emergency medical service). 
Table 2 COVID-19 Suspected Patients Treated by the Emergency Services PRU* and HEMS**

\begin{tabular}{|c|c|c|c|c|c|c|c|c|}
\hline & Sex & Age & $\begin{array}{l}\text { COVID-I9- } \\
\text { Infection } \\
\text { Identified } \\
\text { Prehospitally }\end{array}$ & Initial Symptoms & $\begin{array}{c}\text { COVID } \\
\text { Confirmed }\end{array}$ & Treatment & Death & $\begin{array}{c}\text { Emergency } \\
\text { Services }\end{array}$ \\
\hline Patient I & $\sigma^{2}$ & 54 & No & $\begin{array}{l}\text { Dyspnea, oxygen saturation } \\
<90 \% \text {, cough, fever }>38.5^{\circ} \mathrm{C}\end{array}$ & Positive & $\begin{array}{l}\text { Oxygen and volume } \\
\text { supply, admitted to } \\
\text { ICU }\end{array}$ & No & PRU* \\
\hline Patient 2 & q & 53 & No & $\begin{array}{l}\text { Dyspnea, oxygen saturation } \\
<90 \% \text {, cough, fever }>38.5^{\circ} \mathrm{C}\end{array}$ & Negative & $\begin{array}{l}\text { Oxygen and volume } \\
\text { supply, admitted to } \\
\text { ICU }\end{array}$ & No & PRU* \\
\hline Patient 3 & 우 & 89 & No & $\begin{array}{l}\text { Dyspnea, oxygen saturation } \\
>90 \% \text {, cough, no fever }\end{array}$ & Negative & $\begin{array}{l}\text { Oxygen and volume } \\
\text { supply, admitted to } \\
\text { a normal ward }\end{array}$ & Yes & PRU* \\
\hline Patient 4 & q & 83 & No & $\begin{array}{l}\text { Dyspnea, oxygen saturation } \\
<90 \% \text {, cough, fever }>38.5^{\circ} \mathrm{C}\end{array}$ & Positive & $\begin{array}{l}\text { NIV, volume supply, } \\
\text { admitted to ICU }\end{array}$ & Yes & PRU* \\
\hline Patient 5 & ๙ & 58 & No & $\begin{array}{l}\text { Dyspnea, oxygen saturation } \\
<90 \% \text {, cough, fever }>38.5^{\circ} \mathrm{C} \text {, } \\
\text { cardiovascular arrest }\end{array}$ & Negative & $\begin{array}{l}\text { Resuscitation, } \\
\text { admitted to ICU }\end{array}$ & Yes & PRU* \\
\hline Patient 6 & ๙ & 83 & Yes & $\begin{array}{l}\text { Dyspnea, oxygen saturation } \\
<90 \% \text {, cough, fever }>38.5^{\circ} \mathrm{C}\end{array}$ & Positive & $\begin{array}{l}\text { Oxygen and volume } \\
\text { supply, admitted to } \\
\text { ICU }\end{array}$ & Yes & PRU* \\
\hline Patient 7 & 3 & 80 & No & $\begin{array}{l}\text { Dyspnea, oxygen saturation } \\
<90 \% \text {, cough, fever }>38.5^{\circ} \mathrm{C}\end{array}$ & Positive & $\begin{array}{l}\text { Oxygen and volume } \\
\text { supply, admitted to } \\
\text { ICU }\end{array}$ & No & PRU* \\
\hline Patient 8 & ๙ & 45 & No & $\begin{array}{l}\text { Dyspnea, oxygen saturation } \\
<90 \% \text {, cough, no fever }\end{array}$ & Positive & $\begin{array}{l}\text { Oxygen and volume } \\
\text { supply, admitted to } \\
\text { ICU }\end{array}$ & No & PRU* \\
\hline Patient 9 & o & 81 & No & $\begin{array}{c}\text { No Dyspnea, oxygen } \\
\text { saturation }>90 \% \text {, fever }>38.5^{\circ} \\
\text { C }\end{array}$ & Positive & $\begin{array}{l}\text { Oxygen and volume } \\
\text { supply, admitted to } \\
\text { a normal ward }\end{array}$ & No & PRU* \\
\hline Patient 10 & 우 & 93 & No & $\begin{array}{l}\text { Dyspnea, oxygen saturation } \\
<90 \% \text {, cough, no fever }<38^{\circ} \mathrm{C}\end{array}$ & Positive & $\begin{array}{l}\text { Oxygen and volume } \\
\text { supply, admitted to } \\
\text { a normal ward }\end{array}$ & Yes & PRU* \\
\hline Patient II & 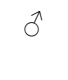 & 96 & No & $\begin{array}{c}\text { Bradycardia and } \\
\text { cardiovascular arrest }\end{array}$ & Negative & Resuscitation & Yes & HEMS** \\
\hline Patient 12 & o & 95 & No & $\begin{array}{l}\text { Dyspnea, oxygen saturation } \\
<90 \% \text {, cough, fever }>38.5^{\circ} \mathrm{C}\end{array}$ & Negative & $\begin{array}{l}\text { Oxygen and volume } \\
\text { supply, admitted to } \\
\text { a normal ward }\end{array}$ & No & HEMS** \\
\hline
\end{tabular}

Notes: $q=$ female, $\delta=$ male.

Abbreviations: ICU, intensive care unit; *PRU, physician response unit; **HEMS, air ambulance (helicopter emergency medical service).

related to COVID-19 the case fatality proportion ${ }^{5,6}$ was calculated for Germany, its selected states and counties as well as cities (Tables 2 and 3) and compared to the other countries (USA, Spain, Italy and France).

\section{COVID-19 Disease in Hannover}

We assessed publicly available data from local authorities, and from the Robert Koch-Institut (RKI) ${ }^{11}$ in Hamburg. For comparison of CFP (case fatality proportion) values of European 
Table 3 Demographic Figures Related to COVID-19 Infections and Deaths for the International Comparison Based on Data from the Johns Hopkins University' (as of March 3, 2020)

\begin{tabular}{|l|l|l|l|}
\hline Countries & Death (n) & Infections (n) & CFP*2,3 \\
\hline USA & 68,957 & $1,192,906$ & 0.058 \\
Italy & 28,884 & 210,717 & 0.137 \\
Spain & 25,428 & $248,30 I$ & 0.102 \\
France & 24,895 & 168,693 & 0.148 \\
Germany & 6,866 & 165,745 & $0.04 I$ \\
\hline
\end{tabular}

Abbreviation: *CFP, case fatality proportion.

countries and the USA, data from Johns Hopkins University \& Medicine Coronavirus Resource Center ${ }^{12}$ was used.

\section{Statistical Methods}

Statistical analysis was performed using SPSS 26 (IBM, SPSS Inc., Chicago, IL). For dichotomous variables, the Fisher's exact test was used. For mean variables, the Mann-Whitney $U$-test was used after checking for normal distribution. Significance value was set to $\mathrm{p}<0.05$.

\section{Results}

\section{Participants}

From March 16 to April 16 in 2018, 2019 and 2020 $\mathrm{n}=1133$ rescue missions were recorded. 1004 patients were included for evaluation of patient data (Figure 1). The only exclusion criterion for patient data was a mission being canceled before arrival at the scene. All included patients had complete data sets. Figure 1 shows a flow chart of the study design.

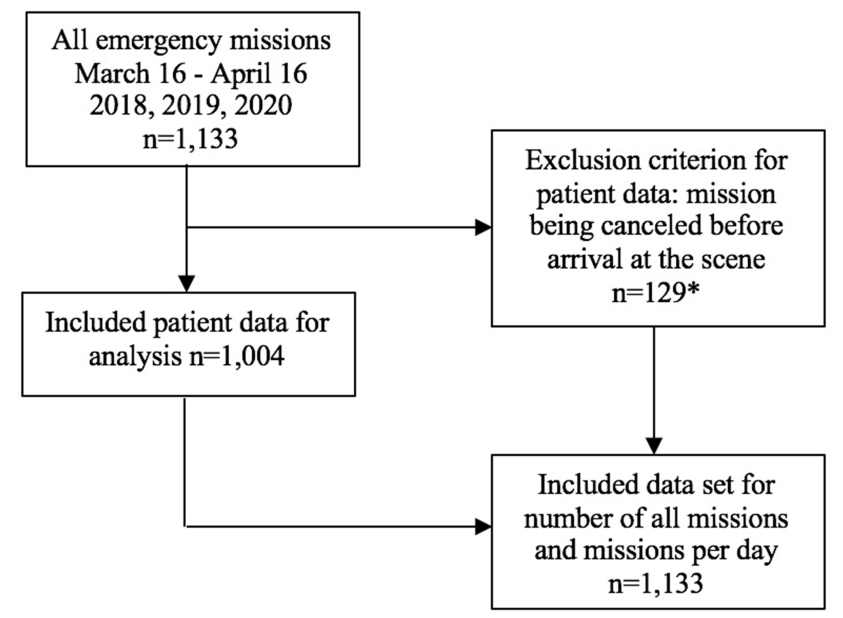

Figure I Flow chart of the inclusion and exclusion criteria for the cohort. *The proportion of $10 \%$ cancelled missions is comparable throughout the years (data not shown).

\section{Main Results}

The average age of the total cohort was $62.3 \pm 24.8$ years. Patients treated by HEMS (air ambulance [helicopter emergency medical service]) were on average 3.5 years younger (HEMS: $59.9 \pm 25.5$ vs PRU: $63.6 \pm 24.3$, $\mathrm{p}=0.027$ ). Comparing 2018 to 2019 and 2020 respectively, patients treated by HEMS became also significantly younger over the years $(2018: 63.4 \pm 25.8 ; 2019: 60.1 \pm 25.9, \mathrm{p}=0.131$; 2020: $54.9 \pm 23.9, \mathrm{p}=0.011$; both compared to 2018). The age of patients treated by PRUs (physician response unit) increased significantly compared to 2018 and 2019 (2018: 61.5 $\pm 25.3 ; 2019$ : 63 $\pm 24.9, \mathrm{p}=0.118 ; 2020 ： 66.6 \pm 22.1$, $\mathrm{p}=0.029$; both compared to 2018).

Five hundred and seventy-six (56.5\%) of the 1004 patients were male. The subgroup analysis of HEMS and PRU showed that significantly more men than women were treated by HEMS (228 (65.3\%) vs 121 (34.7\%), $\mathrm{p}<0.001)$. The gender distribution within the subgroups did not vary significantly (PRU 2018-2020: men: 46.456.2\%, women: 43.8-53.6\%; $\mathrm{p}=0.09$; HEMS 2018-2020: men: $61.7-72.2 \%$, women: $27.8-38.3 \%$; $\mathrm{p}=0.237$ ). Figure 2 shows the gender distribution within PRUs and HEMS cumulated for 2018 to 2020 .

In the study period of $2018 \mathrm{n}=21,008,2019 \mathrm{n}=18,946$ and $2020 \mathrm{n}=17,360$ emergency calls (objective 1) were registered, respectively. The assessment of the total number of rescue missions in the City and Region of Hanover showed $n=12,564$ missions in the analyzed period for 2018, $\mathrm{n}=13,070$ for 2019 and $\mathrm{n}=9,973$ for 2020. This amounts to a reduction of $22 \%$.

The number of emergency missions (objective 2) in $2020(\mathrm{n}=333)$ decreased by about $17 \%$ compared to 2018 $(n=403)$ and $2019 \quad(n=397)$. The amount of missions

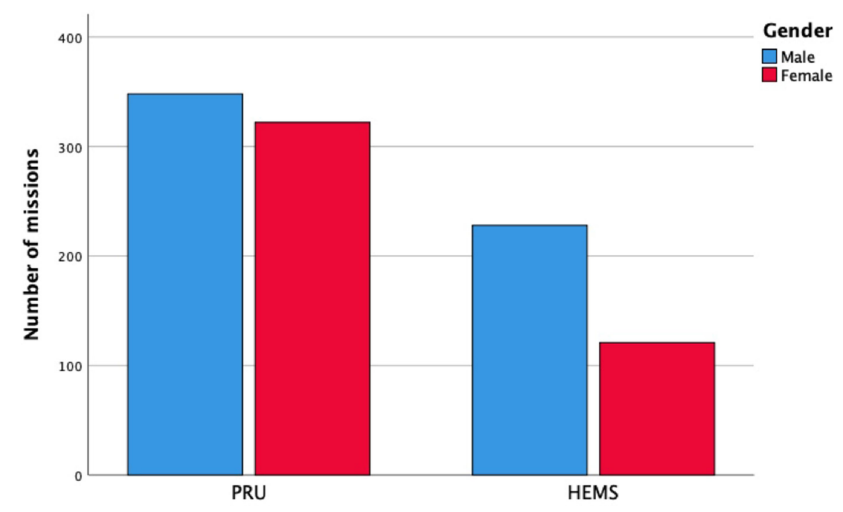

Figure 2 Bar chart for graphical representation of gender distribution, separated into the subgroups PRU and HEMS. 
per day in 2020 declined significantly compared to previous years to $3.53 \pm 1.30$ (2018: $4.41 \pm 1.60 ; \mathrm{p}=0.019$; 2019: $4.31 \pm 1.71 ; \mathrm{p}=0.044)$ for HEMS and to $6.88 \pm 1.66$ (2018: 8.19 $\pm 1.66 ; \mathrm{p}=0.002 ; 2019: 8.09 \pm 2.67 ; \mathrm{p}=0.032$ ) for PRUs. However, medical reasons for emergency physician missions did not change significantly over time (Table 1).

A total of $n=150(14.9 \%)$ missions were due to respiratory emergencies (objective 3 ), with HEMS $(n=22,5.6 \%$ ) treating significantly fewer respiratory emergencies than PRU ( $\mathrm{n}=128,19.1 \%, \mathrm{p}<0.001)$. However, there was no difference in the number of respiratory emergencies in 2020 compared to previous years (2020: HEMS $n=3$ (3.1\%), PRU n=35 (17.5\%)).

In $2020 \mathrm{n}=10$ patients $(28.6 \%)$ with COVID-19 (objective 4) associated complaints were treated by the PRU of Hannover Medical School. None of the COVID-associated cases died in the prehospital phase but in three cases severe respiratory failure had to be managed by two times endotracheal intubation and one times non-invasive ventilation (NIV). When NIV was used for respiratory support in the preclinical phase, a COVID-19 infection of the attending physician occurred. In this case there was a relative indication for an intubation. It was up to his/her experience and evaluation of the situation. He/she made the decision for NIV. The clinical findings of these ten patients are shown in Table 2.

The average NACA (National Advisory Committee for Aeronautics) score (objective 5) of the total cohort was $3.52 \pm 1.36$. The comparison of the complete NACA score (PRU and HEMS) for both rescue services for the years 2018 and 2019 showed no significant difference (2018: $3.39 \pm 1.28,2019$ : $3.44 \pm 1.32, \mathrm{p}=0.625$ ). However, for the period under investigation in 2020, a significant increase in the NACA score was found compared to the same periods in 2018 and $2019(3.76 \pm 1.47, \mathrm{p}=0.004$ compared to $2019, \mathrm{p}=0.001$ compared to 2018 ).

The subgroup analysis showed that the NACA score was significantly higher for HEMS than in the PRU group (3.64 \pm 1.43 vs $3.46 \pm 1.32 ; \mathrm{p}=0.048)$.

While in the PRU group the COVID-19 pandemic did not have a significant impact on the NACA score (Figure 3, 2018: 3.45 $\pm 1.24 ; 2019: 3.39 \pm 1.32, \mathrm{p}=0.632 ; 2020: 3.54$ \pm 1.40 ; $\mathrm{p}=0.450$; each compared to 2018 ), the NACA score for HEMS increased significantly in 2020 (2018: 3.30

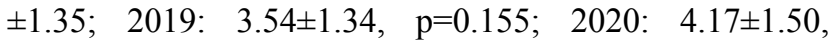
$\mathrm{p}<0.001$; each compared to 2018).

In total, prehospital deaths (objective 6) were recorded in $78(7.8 \%)$ patients. Mortality did not differ significantly between years $(2018 n=22,6.2 \% ; 2019 n=32,9.1 \% ; 2020$

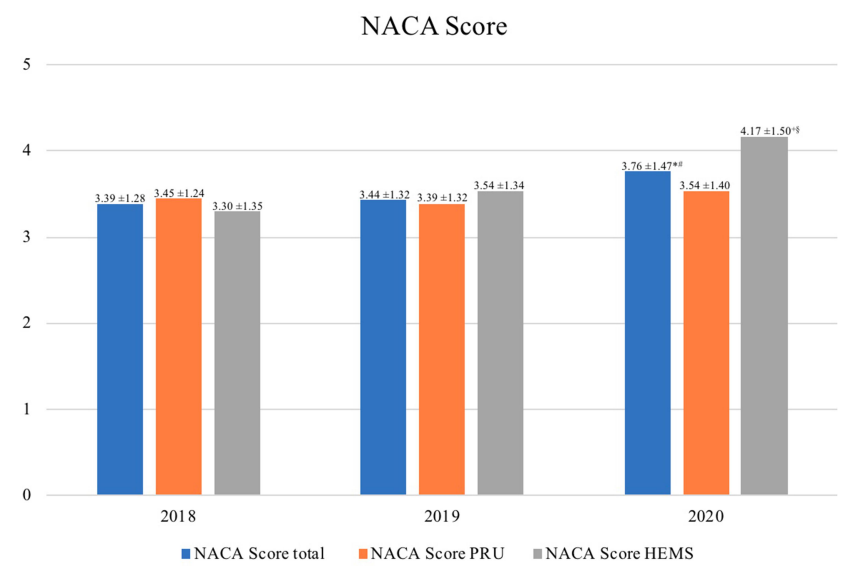

Figure 3 Graphical display of the NACA Score for PRU and HEMS as well as for the whole cohort; ${ }^{*} \mathrm{p}=0.0012020$ vs $2018 ;{ }^{*} \mathrm{p}=0.0042020$ vs $2019 ;{ }^{+} \mathrm{p}<0.0012020$ vs $2018,{ }^{\S} \mathrm{p}=0.0012020$ vs 2019 .

$\mathrm{n}=24,8.2 \% ; \mathrm{p}=0.332)$. There were also no differences in rescue missions related to mortality for 2020, neither between the years nor between HEMS $(n=8,8.6 \%)$ and PRU ( $\mathrm{n}=16,8.0 \%, \mathrm{p}=0.88)$. Data clarifying death by COVID-19 was not available for these patients.

To assess the severity of disease in the districts and states as well as for international comparison, the CFP values are shown in detail in Tables 3 and 4.

\section{Discussion}

\section{Key Results}

In summary, our study shows a significant reduction in the number of PRU and HEMS missions per day and a significant increase in the severity of the disease in HEMS cases. The number of emergency missions handled by the control room for the period under investigation in 2020 compared to the same period in 2018 and 2019 decreased by $17 \%$. We observed no excessive increase of interventions due to respiratory or COVID-19 associated complaints. The number of respiratory non-COVID-19 associated emergencies did not change significantly compared to 2018 and 2019. The same applies to the number of deaths.

\section{Strengths and Limitations}

For the data assessment of the study, we decided to analyse the period when the lockdown took place in Germany. At this time we expected the strongest impact of COVID19 on people. In addition, the quarantine measures were carried out for this period and thus external disturbance factors as sources of infection, such as an increased risk of infection by returning holidaymakers or foreigners 


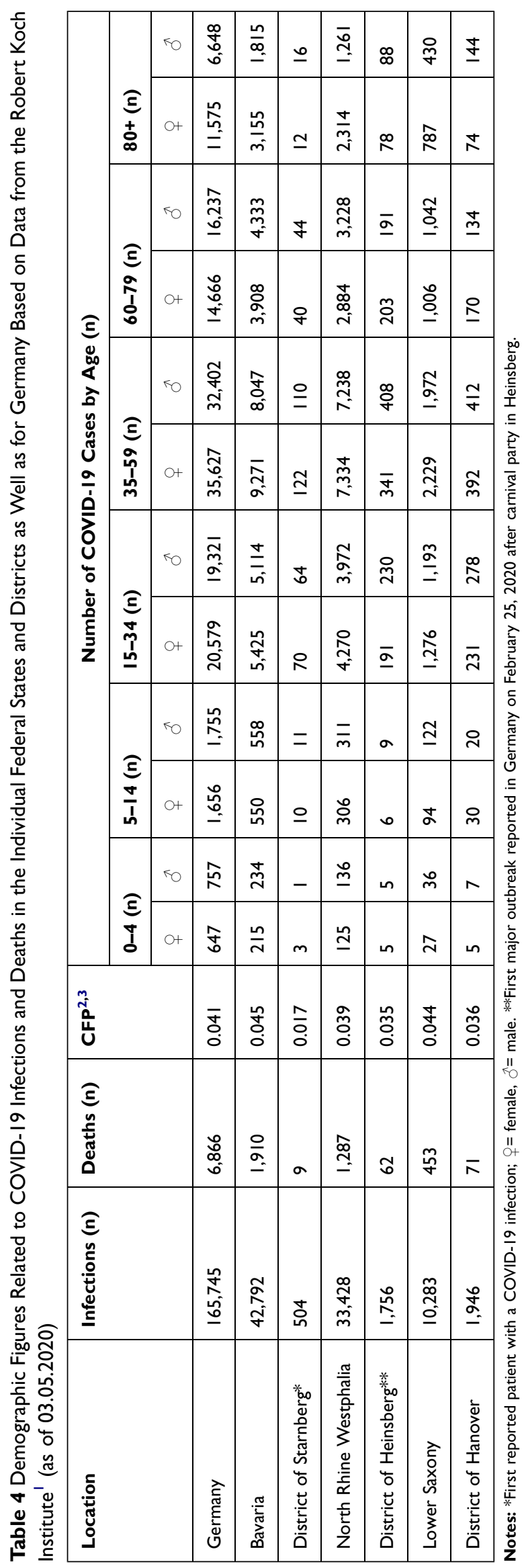

entering the country as well as increased social contacts, were reduced.

The used cohort $(\mathrm{n}=1004)$ was made as a single center study up from two of six physician staffed services of Hanover city. Therefore, a selection bias could be possible. The study size was derived from the calls processed in the control room run by Hanover Fire Department for the above mentioned period. In this context, it should be mentioned that only certain keywords provide the indication for the deployment of a PRU (physician response unit) or HEMS (air ambulance [helicopter emergency medical service]). These are for example severe chest pain, serious injuries, eg, in traffic accidents, but also acute respiratory distress, eg, in COPD, as well as symptoms of a potential COVID-19 infection.

Nevertheless, as far as the selection of the data origin is concerned, the only limiting factor is the affiliation of the rescue services to the authors' hospital. The control room of Hanover Fire department is completely independent, therefore the data are reliable and objective. Thus, neither the reason for alerting nor the frequency of deployment or the decision which emergency service was sent out could be influenced. Within the scope of our investigation, the detailed clinical pictures of the rescue operations could not be analyzed separately. This is due to the fact that prehospital diagnoses are made based on telephone information only. It could neither be revised on scene or in hospital, and could not be assessed by us later. Therefore, the missions are divided into six categories: traumatology, internal medicine, neurology, psychiatric, pediatric or gynecological, without further explanation of clinical symptoms (Table 1).

For a better classification and objectivity of our results, we calculated the CFP. CFP is evaluated in the literature as a valid epidemiological parameter, ${ }^{5,6}$ and is a simple indicator to assess the severity of the pandemic. The higher this parameter is, the more severe is the impact of the disease on the population. Thus, countries, states and regions as well as cities can be easily compared.

In order to present data which are as objective as possible, the selection of these three states as a comparative cohort is justified by the fact that the western (North Rhine-Westfalia with a major outbreak after a carnival party in Heinsberg on February 27, 2020) and southeastern parts of Germany (Bavaria with the first COVID-19 patient in Germany on January 28, 2020) showed a higher incidence and mortality compared to the nationwide infection numbers. In addition, there is 
a geographical proximity between Bavaria and Northern Italy, which had been badly affected by the COVID-19 pandemic. For international comparison, the infection and death figures due to COVID-19 of the USA, Italy, Spain and France were used. At the time of the data collection these countries were seriously affected by the COVID-19 pandemic, although, with the exception of the USA, in these European neighbouring countries, nearly comparable health services and socio-economic standards as in Germany, existed. Nevertheless, due to less ICU beds and ventilators per 100,000 citizen the comparability could be relatively limited and this has indeed an impact on the CFP and leads to more worse CFP rates in Italy, Spain and France than in Germany.

\section{Interpretation}

COVID-19 takes on a special role, as it not only acts as a final diagnosis in the sense of an upper respiratory tract infection, but also as a secondary powerful contributor. In addition to the primary effect of the disease, it can also have a secondary effect, intensified by quarantine measures, on the avoidance behavior of patients in the sense of fear of an increased risk of infection with COVID-19, eg, through close contacts, especially in hospitals. The closure of schools, pre-schools, day-care centers and sports clubs has led to a reduction in everyday activities and thus to a lower risk of acquiring infections at school, during sports activities and on the daily commute. Nevertheless, our data showed even a reduction across all types of rescue missions, so that we could not confirm this effect. Despite this, an increase in the severity of illness of the NACA (National Advisory Committee for Aeronautics) score could be shown for HEMS (air ambulance [helicopter emergency medical service]). This could be due to the fact that the patients with minor illnesses did not call the emergency services out of fear and thus a shift to higher NACA values occurred. However, it could also be an expression of the time delay until the emergency call is made since patients wait and only call when the symptoms are more severe. These circumstances could have led to a reduction in the use of emergency medical services as well as greatly delayed decision making until the emergency consultation occurred. These facts could also explain the reduction in the number of interventions. This is also confirmed by the reduced number of emergency calls. Nevertheless, the quarantine situation may have led to a reduced stress situation in addition to avoidance behavior, which could also explain the reduction of ambulance requests.

Whereas Marijon et al showed a significant increase in out-of-hospital cardiac arrest incidence, coupled with a reduction in survival during the specified time period of the pandemic when compared with the equivalent time period in previous years with no pandemic, ${ }^{13}$ Trabattoni et al reported that there has been a demonstrable reduction of about $25 \%$ in the treatment of heart attacks. ${ }^{8}$ This would be in line with our results, as we were also able to prove a reduction in the number of treatments for the abovementioned period. But this is contradicted by a UK (United Kingdom) study, which reports no changes in the number of heart attacks and strokes. ${ }^{14}$ Also, Baldi et al showed a cumulative incidence of diagnosed Covid-19 and cases of out-of-hospital cardiac arrests in Italy. Furthermore, the authors showed that the cumulative incidence of out-of-hospital cardiac arrests in 2020 was strongly associated with the cumulative incidence of COVID-19. The number of cases of out-of-hospital cardiac arrests compared to 2019 increased also. ${ }^{15}$ These findings may be explained with different CFPs (case fatality proportion) in these regions. A region with comparably low CFPs like ours may have a problem with avoidance behavior of the general public, thus reducing the utilization of medical services. Whereas regions with higher CFPs as an expression of more severe courses of the pandemic itself have to deal with COVID linked diseases and deaths, clouding the reduction in utilization of medical services and resulting in equivalent or even higher disease and death rates. ${ }^{16}$

\section{Generalizability}

In assessing external validity, it should be taken in mind that our cohort was analyzed under special conditions (emergency situations). The objectives 1, 2, 3, 4, 5 and 6 were confirmed. This suggests that the pandemic triggered by the SARS-CoV-2 virus had and still has an impact on prehospital care in the German health care system. Equally, COVID-19 also has had an indirect (collateral) impact on the health of citizens in other countries. ${ }^{8,13,15}$

Based on the calculated CFP, a representative classification of our results for the infection and death figures available in Germany at the time of our study was possible. It was noticeable that $17 \%$ fewer emergency medical interventions were carried out in the period under review compared with the same periods in 2018 and 2019. Nevertheless, the NACA score of the emergency medical 
interventions we analyzed increased, so that an effect of the COVID-19 pandemic can until now only be shown with regard to the number of rescue missions and emergency calls.

\section{Conclusion}

We found a decreasing effect of the COVID-19 pandemic in Germany on the number of emergency calls as well as missions, and an increase of the severity of cases in preclinical care for a northern German region with 1.2 million citizens. The effect of these findings caused by COVID-19 on the health care system remains to be seen.

\section{Abbreviations}

CFP, case fatality proportion; Control room, Control center, guidance office for the emergency teams; HEMS, air ambulance, helicopter emergency medical service; $\mathrm{MHH}$, Hannover Medical School; MMWR, Morbidity and Mortality Weekly Report; NACA, National Advisory Committee for Aeronautics; NIV, non-invasive ventilation; PRU, physician response unit; RKI, Robert Koch-Institut; UK, United Kingdom; USA, United States of America.

\section{Transparency}

Availability of data and material: The data sets used and analyzed during the current study are available from the corresponding author on request.

\section{Ethics Approval and Consent to Participate}

Each author certifies that all investigations were conducted in conformity with ethical principles of research. Due to the retrospective data collection ethical approval was given as a waiver (No. 9099_BO_K_2020) and consent was granted by the Ethics Committee of Hannover Medical School.

\section{Acknowledgments}

We thank Hanover Fire Department for offering their help in data collecting.

\section{Funding}

We acknowledge support by the German Research Foundation (DFG) and the Open Access Publication Fund of Hannover Medical School (MHH).

\section{Disclosure}

The authors declare that they have no competing interests.

\section{References}

1. Chung M, Bernheim A, Mei X, et al. CT imaging features of 2019 Novel Coronavirus (2019-nCoV). Radiology. 2020;295:202-207. doi:10.1148/radiol.2020200230

2. Fu L, Wang B, Yuan T, et al. Clinical characteristics of coronavirus disease 2019 (COVID-19) in China: a systematic review and meta-analysis. $J$ Infect. 2020;80:656-665. doi:10.1016/j.jinf.2020. 03.041

3. Linton NM, Kobayashi T, Yang Y, et al. Incubation period and other epidemiological characteristics of 2019 Novel Coronavirus infections with right truncation: a statistical analysis of publicly available case data. J Clin Med. 2020;9:538. doi:10.3390/jcm9020538

4. World Health Organization: Coronavirus disease 2019. (COVID-19) situation report $-87 ; 2020$. Available from: www.who.int/docs/ default-source/coronaviruse/situation-reports/20200416-sitrep-87covid-19.pdf?sfvrsn=9523115a_2. Accessed April 20, 2020.

5. Rothman KJG, Sander L, Timothy L. Modern Epidemiology. Lippincott Williams \& Wilkins (LWW); 2008.

6. Gianicolo E, Blettner M, Karch A, Karch A. Epidemiological measures in the context of the COVID-19 pandemic. Dtsch Arztebl Int. 2020;117:336-342. doi:10.3238/arztebl.2020.0336

7. John Hopkins University of Medicine. Coronavirus Resourse Center. Available from: https://coronavirus.jhu.edu/map.html. Accessed February 15, 2021.

8. Trabattoni D, Montorsi P, Merlino L. Late STEMI and NSTEMI patients' emergency calling in CoVID-19 outbreak. Can J Cardiol. 2020;36:1161.e7-1161.e8. doi:10.1016/j.cjca.2020.05.003

9. Mehra MR, Desai SS, Kuy S, Henry TD, Patel AN. Cardiovascular disease, drug therapy, and mortality in Covid-19. N Engl J Med. 2020;382:2582. doi:10.1056/NEJMc2021225

10. Bramer CA, Kimmins LM, Swanson R, et al. Decline in child vaccination coverage during the COVID-19 pandemic - Michigan care improvement registry, May 2016-May 2020. MMWR Morb Mortal Wkly Rep. 2020;69:630-631. doi:10.15585/mmwr.mm6920e1

11. Robert Koch Instiut.Available from: https://www.rki.de/DE/Content/ InfAZ/N/Neuartiges_Coronavirus/Fallzahlen.html. Accessed February 15, 2021.

12. Robert Koch-Institut: COVID-19-DashboardAvailable from: h t t p s : / experience.arcgis.com/experience/ 478220a4c454480e823b17327b2bf1d4/page/page_1/. Accessed February 15, 2021.

13. Marijon E, Karam N, Jost D, et al. Out-of-hospital cardiac arrest during the COVID-19 pandemic in Paris, France: a population-based, observational study. Lancet Public Health. 2020;5:e437-e443. doi:10.1016/S2468-2667(20)30117-1

14. Holmes JL, Brake S, Docherty M, Lilford R, Watson S. Emergency ambulance services for heart attack and stroke during UK's COVID19 lockdown. Lancet. 2020;395:e93-e94. doi:10.1016/S0140-6736 (20)31031-X

15. Baldi E, Sechi GM, Mare C, et al. Out-of-hospital cardiac arrest during the Covid-19 outbreak in Italy. $N$ Engl $J$ Med. 2020;383:496-498. doi:10.1056/NEJMc2010418

16. Statista. Coronavirus (COVID-19) deaths in Italy as of February 21, 2021, by region.Available from: https://www.statista.com/statistics/ 1099389/coronavirus-deaths-by-region-in-italy/. Accessed February 15, 2021. 


\section{Publish your work in this journal}

The Open Access Emergency Medicine is an international, peerreviewed, open access journal publishing original research, reports, editorials, reviews and commentaries on all aspects of emergency
medicine. The manuscript management system is completely online and includes a very quick and fair peer-review system, which is all easy to use. Visit http://www.dovepress.com/testimonials.php to read real quotes from published authors.

Submit your manuscript here: https://www.dovepress.com/open-access-emergency-medicine-journal 